\title{
Identidade Profissional do Psicólogo: Uma Revisão da Produção Científica no Brasil
}

The Psychologist's Professional Identity: A Review of the Scientific Production in Brazil

Identidad Profesional del Psicólogo: Una Revisión de la Producción Científica en el Brasil

Sheila Maria Mazer \& Lucy Leal Melo-Silva Universidade de São Paulo

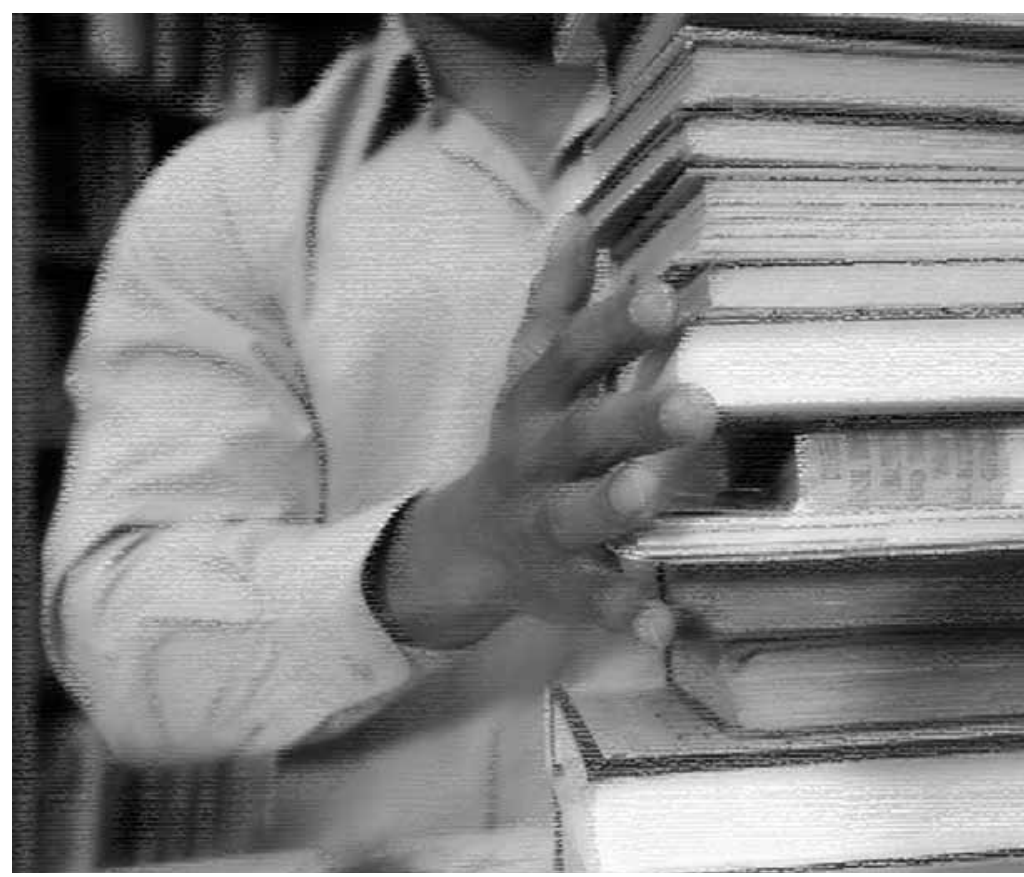


Resumo: Este estudo, do tipo estado da arte, objetiva analisar a produção científica brasileira sobre o tema identidade profissional do psicólogo. Foram analisadas publicações científicas cujo corpo do trabalho continha as palavras-chave: identidade, profissional e psicólogo. Entre 1991 e 2008, foram selecionados 15 artigos publicados em periódicos, 4 dissertações de mestrado, 3 capítulos de livros, 3 resumos publicados em anais de evento científico e 2 teses de doutorado. As publicações foram sistematizadas e classificadas em duas categorias: (1) construção da identidade profissional do psicólogo, com três subcategorias - a escolha da Psicologia como profissão, a formação acadêmica e o exercício da profissão -, e (2) mudanças nos paradigmas no exercício da profissão. Os resultados mostram que a identidade do psicólogo é considerada produto de um conjunto integrado de fatores pessoais e profissionais que influenciam no desenvolvimento da carreira. Além disso, estudos enfatizam a necessidade de mudanças no exercício da profissão, dos paradigmas tradicionais centrados no indivíduo para os ancorados em perspectivas mais sociais, em consonância com a realidade brasileira.

Palavras-chave: Identidade profissional. Psicólogos. Carreira. Formação acadêmica.

\begin{abstract}
This study, of the type "state of the art" type, aims at the analysis of the Brazilian scientific production about the psychologist's professional identity. Scientific papers that contained the keywords: identity, professional and psychologist were analyzed. Publications from 1991 to 2008 were analyzed: 15 articles published in journals, 4 master's theses, 3 chapters from books, 3 abstracts published in the annals of scientific events, and 2 doctorate dissertations. The publications were systematized and classified into two categories: (1) the construction of the psychologist's professional identity, with three subcategories - the choice of psychology as a profession, academic training in psychology and professional practicing, and (2) the paradigm changes in professional practice. The results showed that the psychologist's identity is seen as the outcome of an integrated set of personal and professional factors that influence the development of their career. Besides that, the studies point out the need for change in the professional practice, from traditional paradigms, centered on the individual, into paradigms anchored on social perspectives, which are more in accordance with the Brazilian reality.
\end{abstract}

Keywords: Professional identity. Psychologists. Career. Academic training.

Resumen: Este estudio, del tipo estado del arte, objetiva analizar la producción científica brasileña sobre el tema identidad profesional del psicólogo. Fueron analizadas publicaciones científicas cuyo cuerpo del trabajo contenía las Palabras clave: identidad, profesional y psicólogo. Entre 1991 y 2008, fueron seleccionados 15 artículos publicados en periódicos, 4 disertaciones de mestrado, 3 capítulos de libros, 3 resúmenes publicados en anales de evento científico y 2 tesis de doctorado. Las publicaciones fueron sistematizadas y clasificadas en dos categorías: (1) construcción de la identidad profesional del psicólogo, con tres sub-categorías - la elección de la Psicología como profesión, la formación académica y el ejercicio de la profesión -, y (2) mudanzas en los paradigmas en el ejercicio de la profesión. Los resultados muestran que la identidad del psicólogo es considerada producto de un conjunto integrado de factores personales y profesionales que influencian en el desarrollo de la carrera. Además de eso, estudios enfatizan la necesidad de mudanzas en el ejercicio de la profesión, de los paradigmas tradicionales centrados en el individuo para los anclados en perspectivas más sociales, en consonancia con la realidad brasileña.

Palabras clave: Identidad profesional. Psicólogo. Carrera. Formación académica.

Ao concluir a graduação, o universitário recémformado se dá conta de que sua formação não pode ser considerada completa se forem considerados somente os anos de formação acadêmica universitária. A carreira de estudante possibilitou o alicerce para a construção de um contínuo aprendizado, e é nesse movimento de buscas, descobertas e transformações que o recém-formado vai definindo sua identidade profissional, à medida que vai percorrendo caminhos e construindo sua carreira ao longo da vida. A carreira é definida, neste estudo, como

a combinação e a sequência dos papéis desempenhados por uma pessoa durante o curso de sua vida. Esses papéis incluem os de criança, estudante, cidadão, trabalhador, esposo(a), familiar e aposentado, entre outras posições associadas a expectativas de papéis que são ocupados pela maioria 
A identidade deve ser vista sempre como "metamorfose e como movimento permanente de transformação" (Bock, 1999, p. 315), das pessoas e de outros menos comuns, tais como o de criminoso e o de doente mental, entre outros. (Super, 1980)

Os diversos papéis que um trabalhador desempenha ao longo da vida constroem sua identidade profissional, e, com o psicólogo, como nas demais carreiras, isso não seria diferente. A fim de contribuir com o conhecimento sobre a identidade profissional do psicólogo, o presente estudo focaliza a produção científica existente sobre esse tema na literatura brasileira. Buscar compreender a identidade do psicólogo brasileiro, e o que se publicou sobre o assunto, pode contribuir com as reflexões sobre a formação e os percursos possíveis para se construir as trajetórias profissionais da categoria.

A escolha por produções científicas exclusivamente brasileiras, no presente estudo, se baseia no fato de o psicólogo ser um profissional que lida com as questões emocionais e comportamentais da população, e, portanto, acredita-se que sua identidade e sua práxis sejam construídas em um universo sociocultural específico, nesse caso, na realidade brasileira.

A procura da definição da própria identidade é constante no indivíduo. Para Ciampa (1999), a identidade é um fenômeno social e pode ser entendida como a síntese de múltiplas e distintas determinações; o homem, como ser-no-mundo, busca o desenvolvimento de sua identidade concreta, que define os homens como iguais a uns e diferente de outros, em um constante movimento de mudanças e transformações, que se realizam sob condições históricas e sociais igualmente em movimento.

Identidade é o conceito-chave na teoria de Erik Erikson. As qualidades fundamentais constitutivas da identidade do indivíduo são produtos da resolução de conflitos típicos de certa idade. A formação da identidade "surge do repúdio seletivo e da assimilação mútua de identificações da infância e da absorção destas numa nova configuração" (Erikson, 1987, p. 159). Segundo o autor, a identidade é fixada no final da adolescência e é constituída em relação às identificações singulares com outros indivíduos no passado, e abrange todas as identificações significativas, alterando-as de modo a construir, nesse processo, "um todo único e razoavelmente coeso" (p. 161). A teoria de Erikson não incide diretamente sobre o desenvolvimento vocacional;

contudo, as preferências profissionais e a escolha de uma profissão parecem constituir elementos maiores da 'construção de si', que só tem sentido se referidos aos 'sentimentos de identidade', construídos no curso de certas inteirações num dado momento do desenvolvimento. (Guichard \& Huteau, 2002, p. 156)

Assim, de acordo com Galindo (2004), o indivíduo se define a partir de como se reconhece no desempenho de papéis sociais e de como é reconhecido pelos outros no meio social, propondo esse autor uma perspectiva de construção da identidade de um ponto de vista da relação entre o subjetivo e o social. A identidade deve ser vista sempre como "metamorfose e como movimento permanente de transformação" (Bock, 1999, p. 315), consolidando a definição de um conceito de identidade sempre em construção, considerando-se os múltiplos fatores que intervêm nesse processo, que deve ser levado em conta na história de vida do indivíduo.

Portanto, a identidade pode ser definida como um processo de identificações, em um interjogo entre o autoconceito do indivíduo e de suas representações sociais, isto é, a percepção que tem ele de si mesmo inserido em uma dada sociedade e aquilo que a 
sociedade lhe atribui enquanto característica (Ciampa, 1999; Luna, 2003). Luna (2003), reportando-se a Sawaia (1999), afirma que

existe um paradoxo na concepção de identidade, pois, ao mesmo tempo em que é transformação e multiplicidade, é também permanência e unicidade, o que a torna relativamente estável; a pluralidade humana tem assim um duplo aspecto: igualdade e diferença. O que faz o indivíduo, na aparência, ser sempre o mesmo, não estar constantemente em movimento, é o fato de que as mudanças ocorrem, na maioria das vezes, de forma paulatina. (Luna, 2003, p.91)

Apresentar algumas definições sobre identidade é útil no sentido de circunscrever o campo no qual a identidade profissional será analisada neste estudo. A identidade profissional é considerada um dos alicerces da identidade pessoal; é, portanto, um aspecto da identidade do sujeito, parte de um sistema mais amplo que a compreende; é determinada e determinante na relação com toda a personalidade, ou seja, é multiplicidade e unicidade. Sendo compreendida como a autopercepção, ao longo do tempo, em termos de papéis ocupacionais, a identidade profissional vem sendo construída em um processo contínuo (Bohoslavsky, 1991; Luna, 2003; Melo-Silva \& Reis, 1997).

Para Schein (1996), a identidade profissional é representada por pontos de referência profissional, constituindo as áreas de competência, os objetivos e os valores que identificam uma pessoa com determinadas inclinações profissionais. À medida que a pessoa progride em sua carreira, ela adquire um conceito a seu próprio respeito. Esse autoconceito vai se formando pela percepção que o indivíduo adquire a respeito de si mesmo a partir das experiências e por aquilo que considera suas aptidões, interesses e habilidades.

\begin{abstract}
A escolha de uma carreira ou de um trabalho deve implementar o autoconceito e conferir uma identidade social significativa para o indivíduo, ao permitir que ele possa contribuir produtivamente para a comunidade e, assim, tornar-se autosuficiente, bem-sucedido, satisfeito, estável e saudável em sua vida pessoal. (Savickas, 2001, citado por Jenschke, 2003)
\end{abstract}

Dimenstein (2000) e Figueiredo (1993) afirmam que há, historicamente, uma ênfase na singularidade de cada psicólogo, de cada percurso e experiência individual, e que isso tem ressonância também quanto à questão da identidade profissional do psicólogo, que parece ser cada vez mais difícil de ser definida. De acordo com Dimenstein (2000), a diversidade constitutiva do ser psicólogo não permitiria a criação de uma identidade única para a categoria.

Ainda que seja possível concordar em parte com Dimenstein e falar de identidades, cumpre destacar que o conceito de identidade, de acordo com os referenciais teóricos metodológicos utilizados neste estudo, consideram a multiplicidade e a unicidade na compreensão do conceito. Assim, de acordo com Ciampa (1999), como apontado anteriormente, a identidade define os homens como iguais a uns e diferentes de outros, em um constante movimento de mudanças e transformações, que se realizam sob condições históricas e sociais igualmente em movimento. Além disso, para Erikson (1987, p. 161) a identidade é constituída em relação às identificações singulares com outros indivíduos, abrangendo identificações significativas, que se alteram de modo a construir, nesse processo dinâmico, "um todo único e razoavelmente coeso". É na perspectiva de uma certa coesão em termos de identidade, com base em Erikson, que se concebe o presente estudo. Evidentemente, considera-se que o significado do que é razoavelmente coeso inclui as diferenças que 
existem em uma ampla categoria de psicólogos, constituída pelas singularidades.

Nas semelhanças e diferenças, a preparação acadêmica dos profissionais psicólogos, com a crescente aceitação de modelos alternativos de formação, novos papéis, consciência social e diversidade nos assuntos da profissão, implica grandes mudanças para a profissão do psicólogo no século XXI, como destaca Yalof (2004).

Na perspectiva de Martin-Baró (1996) o trabalho do psicólogo deve ser definido em função das circunstâncias concretas da população a que deve atender. Pode-se afirmar que o trabalho do psicólogo brasileiro, sua formação e sua trajetória profissional diferem daqueles de psicólogos em outros países, dado que há uma relação entre a população atendida e a cultura profissional. Por sua vez, Dimenstein (2000) afirma que a cultura profissional pode ser definida como o conjunto de ideias, de visão de mundo e de estilo de vida profissional que é adotado por um grupo profissional específico. Isso vem determinar a adesão e a preferência por certos modelos de atuação e referenciais teóricos. Tais atitudes definem as formas de organização e representação na sociedade e o exercício da atividade profissional, da rotina de trabalho.

Considerando que o trabalho ocupa um papel preponderante na construção da identidade profissional do sujeito, como aponta Krawulski (2004), esta, então, pode ser definida como a representação que o sujeito faz de si próprio, e que os demais atribuem a ele, no que se refere ao trabalho que realiza. De acordo com Luna (2003), as questões relativas à identidade profissional obrigatoriamente devem remeter ao mundo do trabalho, às profissões, às suas transformações e contradições.

Nesse sentido, a Psicologia, como carreira, constitui o ponto de partida da identidade profissional do psicólogo. Focalizar a identidade do psicólogo brasileiro é útil no sentido de conhecer em maior profundidade a carreira, a multiplicidade de áreas de atuação e as possibilidades de trajetórias pessoais e profissionais. Assim sendo, este estudo objetiva analisar a produção científica brasileira sobre o tema identidade profissional do psicólogo a fim de contribuir com o conhecimento na área da Psicologia no cenário brasileiro.

\section{Método}

O presente estudo é do tipo estado da arte ou estado do conhecimento, que constitui uma opção metodológica constituída em pesquisa de levantamento e de avaliação do conhecimento sobre um determinado tema, no caso, a identidade profissional do psicólogo. Ferreira (2002) define estado da arte ou estado do conhecimento como pesquisas de caráter bibliográfico, que têm em comum o desafio de mapear e discutir certa produção acadêmica em diferentes campos do conhecimento, tentando responder que aspectos e dimensões vêm sendo destacados e privilegiados em diferentes épocas e lugares, de que formas e em que condições têm sido produzidas certas dissertações de mestrado, teses de doutorado, publicações em periódicos e comunicações em anais de congressos e de seminários. A autora ainda coloca que a pesquisa do tipo estado da arte representa

\footnotetext{
uma metodologia de caráter inventariante e descritivo da produção acadêmica e científica sobre um tema que busca investigar, à luz de categorias e facetas que se caracterizam enquanto tais em cada trabalho e no conjunto deles, sob os quais o fenômeno passa a ser analisado. (Ferreira, 2002, p. 258)
}

No caso da presente pesquisa, um estudo do tipo estado da arte procurou mapear a produção acadêmica sobre o tema identidade profissional do psicólogo, buscando descrever e analisar os estudos encontrados e selecionados. Trata-se de um estudo ilustrativo, e não representativo. 


\section{Procedimentos de obtenção dos dados}

Sendo o propósito deste estudo uma revisão da literatura do tipo estado da arte, procedeu-se a um levantamento bibliográfico, no Brasil, da produção científica existente sobre a identidade profissional do psicólogo. A busca circunscreveu-se a estudos publicados em revistas encontradas em base de dados indexada Scielo Psicologia, a periódicos da área da Psicologia, a livros publicados pela Associação Brasileira de Orientação Profissional (ABOP), a teses, dissertações e anais de eventos publicados no Brasil, encontrados na base de dados Dedalus, da Universidade de São Paulo, e no Portal de Periódicos da Coordenadoria de Aperfeiçoamento de Pessoal de Nível Superior (CAPES), do Ministério da Educação. Buscaram-se trabalhos científicos cujo corpo do trabalho continha as palavras-chave: identidade, profissional e psicólogo. Não houve a preocupação em delimitar o ano da publicação, mas pode-se dizer que foram encontrados trabalhos datados a partir do ano 1991.

\section{Procedimento de análise dos dados: definição das categorias}

Inicialmente, todos os estudos encontrados - período 1991 a 2008 - foram submetidos a uma leitura geral e organizados de acordo com o ano e a natureza da publicação. A seguir, os estudos passaram por uma leitura atenta, buscando-se os pontos de convergência entre os assuntos tratados nos textos, tendo sido formadas, então, categorias e subcategorias temáticas, como descritas a seguir.

Categoria 1. Construção da identidade profissional do psicólogo, em três subcategorias:

- 1.1. A escolha da Psicologia como profissão;

- 1.2. A formação acadêmica em Psicologia, e

- 1.3. O exercício da profissão psicólogo.

Categoria 2. Mudança de paradigma: do individual para o social.

\section{Resultados}

Para fins deste estudo, foram encontrados 15 artigos publicados em periódicos brasileiros; quatro dissertações de mestrado, três capítulos de livros, três resumos publicados em anais de eventos científicos e duas teses de doutorado, totalizando 27 produções analisadas, como mostra a Tabela 1.

Tabela 1. Distribuição dos estudos em função da data e da natureza da publicação

\begin{tabular}{lcccccc}
\hline Período & Artigos & $\begin{array}{c}\text { Dissertaçóes } \\
\text { de mestrado }\end{array}$ & $\begin{array}{c}\text { Capítulos } \\
\text { de livros }\end{array}$ & $\begin{array}{c}\text { Resumos em } \\
\text { anais }\end{array}$ & $\begin{array}{c}\text { Teses de } \\
\text { doutorado }\end{array}$ & Total \\
\hline $1991-2000$ & 8 & 2 & - & 2 & 1 & 13 \\
$2001-2008$ & 7 & 2 & 3 & 1 & 1 & 14 \\
\hline Total & 15 & 4 & 3 & 3 & 2 & 27 \\
\hline
\end{tabular}


Abreu Filho (2000), em seu estudo, ressalta que, em pesquisa bibliográfica sobre a questão da identidade profissional do psicólogo, encontrou poucos trabalhos no Brasil e no exterior. A realização deste estudo, da mesma forma, identificou poucos trabalhos que versam sobre a identidade profissional do psicólogo, revelando que se trata de um campo de pesquisa que necessita de mais estudos. Os trabalhos encontrados datam de publicações sobre o tema que se circunscrevem ao período de 1991 a 2008. Os artigos em periódicos constituem a natureza da publicação na qual foram encontrados mais trabalhos, em detrimento dos outros tipos de publicação, totalizando 15 estudos.

A análise dos dados encontrados possibilitou a definição de categorias e subcategorias temáticas, de acordo com a convergência dos objetos de investigação. Na categoria temática 1. Construção da identidade profissional do psicólogo, a identidade profissional do psicólogo é tratada como um processo de construção de sujeitos como profissionais. Nessa categoria, é possível descrever três subcategorias: (1) a escolha da Psicologia como profissão, (2) a formação acadêmica em Psicologia e (3) o exercício da profissão psicólogo. De forma geral, a construção da identidade profissional do psicólogo inclui a questão da escolha da Psicologia como profissão e o significado de ser psicólogo em um primeiro momento, para ir se consolidando durante a formação acadêmica e posteriormente na vivência como profissional, no fazer cotidiano.

As Tabelas 2, 3, 4 e 5 mostram a distribuição dos estudos em função das categorias e subcategorias temáticas. As publicações estão organizadas por ordem cronológica, em função de cada categoria e da distribuição dos estudos segundo autor, ano de publicação, título, natureza da publicação, local/ editora e síntese do resumo do estudo.

A Tabela 2 apresenta a distribuição dos estudos relacionados à categoria 1. Construção da identidade profissional do psicólogo e à subcategoria 1.1. A escolha da Psicologia como profissão $(n=3)$. Foram reunidas nessa categoria as publicações de Abreu Filho (2000), Magalhães (2001) e Krawulsky e Patrício (2005). É possível perceber que foram localizados poucos trabalhos que tratam da escolha da Psicologia como profissão e do significado dessa escolha na construção da identidade profissional do futuro psicólogo.

Tabela 2. Distribuição dos estudos referentes à subcategoria 1.1. A escolha da Psicologia como profissão, segundo autor, ano de publicação, título, natureza da publicação, local/editora e síntese do estudo.

\begin{tabular}{|c|c|c|c|c|c|}
\hline Autor & $\begin{array}{c}\text { Ano de } \\
\text { publicação }\end{array}$ & Título & $\begin{array}{l}\text { Natureza da } \\
\text { publicação }\end{array}$ & Local/Editora & Síntese do estudo \\
\hline $\begin{array}{l}\text { Abreu } \\
\text { Filho }\end{array}$ & 2000 & $\begin{array}{l}\text { Identidade: a } \\
\text { questão da } \\
\text { identidade de } \\
\text { profissional do } \\
\text { psicólogo }\end{array}$ & Artigo científico & $\begin{array}{l}\text { São Paulo, SP: } \\
\text { Revista Psic }\end{array}$ & $\begin{array}{l}\text { A partir do referencial teórico } \\
\text { psicanalítico kleiniano, o estudo } \\
\text { mostra como as primeiras relações } \\
\text { objetais influenciam na escolha } \\
\text { da Psicologia como profissão } \\
\text { e na construção da identidade } \\
\text { profissional. }\end{array}$ \\
\hline Magalhães & 2001 & $\begin{array}{l}\text { "Eu quero } \\
\text { ajudar as } \\
\text { pessoas": } \\
\text { a escolha } \\
\text { vocacional da } \\
\text { Psicologia }\end{array}$ & $\begin{array}{l}\text { Resumos em anais } \\
\text { do IV Simpósio } \\
\text { Brasileiro de } \\
\text { Orientação } \\
\text { Vocacional \& } \\
\text { Ocupacional }\end{array}$ & $\begin{array}{l}\text { São Paulo, SP: } \\
\text { ABOP }\end{array}$ & $\begin{array}{l}\text { Investiga o processo de escolha } \\
\text { voccional da Psicologia, situada } \\
\text { como profissão de ajuda ou de } \\
\text { orientação social. }\end{array}$ \\
\hline $\begin{array}{l}\text { Krawulski } \\
\text { e Patrício }\end{array}$ & 2005 & $\begin{array}{l}\text { Porque pessoas } \\
\text { escolhem a } \\
\text { Psicologia como } \\
\text { progissão? }\end{array}$ & Capítulo de livro & $\begin{array}{l}\text { São Paulo, SP: } \\
\text { Vetor }\end{array}$ & $\begin{array}{l}\text { Compreender os motivos que } \\
\text { levam pessoas a escolherem a } \\
\text { Psicologia como profissão, tendo } \\
\text { em vista questões altruístas como } \\
\text { motivadoras da escolha }\end{array}$ \\
\hline
\end{tabular}


A Tabela 3 apresenta a distribuição dos estudos relacionados à categoria 1. Construção da identidade profissional do psicólogo e à subcategoria 1.2. A formação acadêmica em Psicologia $(n=9)$. Foram reunidos nessa categoria os estudos de Vilela (1996), Melo-Silva e Reis (1997), Olenscki e Salibe (1998), Yamamoto (1998), Melo-Silva (1999), Aguirre et al. (2000), Melo-Silva e Santos (2003), Ferreira Neto e Penna (2006), e Scorsolini-Comin, Souza, \& Santos (2008). Nota-se maior distribuição de estudos, em relação ao ano de publicação, que versam sobre esse tema, além de uma variação também em relação à natureza das publicações.

Tabela 3. Distribuição dos estudos referentes à subcategoria 1.2. A formação acadêmica em Psicologia, segundo autor, ano de publicação, título, natureza da publicação, local/editora e síntese do estudo.

\begin{tabular}{|c|c|c|c|c|c|}
\hline Autor & $\begin{array}{l}\text { Ano de } \\
\text { publicação }\end{array}$ & Título & $\begin{array}{l}\text { Natureza da } \\
\text { publicação }\end{array}$ & Local/Editora & Síntese do estudo \\
\hline Vilela & 1996 & $\begin{array}{l}\text { Formar-se } \\
\text { psicólogo: como } \\
\text { ser livre como } \\
\text { um pássaro }\end{array}$ & $\begin{array}{l}\text { Tese de } \\
\text { doutorado }\end{array}$ & $\begin{array}{l}\text { São Paulo, SP: } \\
\text { Programa de } \\
\text { Pós-Graduação em } \\
\text { Psicologia Escolar e } \\
\text { do Desenvolvimento } \\
\text { Humano, Universidade } \\
\text { de São Paulo }\end{array}$ & $\begin{array}{l}\text { Faz crítica ao modelo de } \\
\text { formação do psicólogo } \\
\text { e focaliza os estágios } \\
\text { supervisionados na graduação } \\
\text { como importantes espaços de } \\
\text { formação do ser psicólogo. }\end{array}$ \\
\hline $\begin{array}{l}\text { Melo-Silva } \\
\text { e Reis }\end{array}$ & 1997 & $\begin{array}{l}\text { A identidade } \\
\text { profissional em } \\
\text { estudantes do } \\
\text { curso de Psicologia: } \\
\text { intervenção através } \\
\text { da técnica de } \\
\text { grupo operativo }\end{array}$ & $\begin{array}{l}\text { Anais III do } \\
\text { Simpósio } \\
\text { Brasileiro de } \\
\text { Orientação } \\
\text { Vocacional/ } \\
\text { Profissional }\end{array}$ & $\begin{array}{l}\text { Canoas, SP: } \\
\text { ABOP }\end{array}$ & $\begin{array}{l}\text { Descreve e analisa a } \\
\text { construção da identidade } \\
\text { profissional do psicólogo em } \\
\text { estudantes de Psicologia em } \\
\text { momento de crise de saída da } \\
\text { universidade. }\end{array}$ \\
\hline $\begin{array}{l}\text { Olenscki e } \\
\text { Salibe }\end{array}$ & 1998 & $\begin{array}{l}\text { Identidade } \\
\text { profissional. A } \\
\text { metamorfose: de } \\
\text { lagarta a borboleta }\end{array}$ & $\begin{array}{l}\text { Resumo em } \\
\text { anais Encontro } \\
\text { Estadual de } \\
\text { Clínicas-escola }\end{array}$ & Itatiba, SP: USF & $\begin{array}{l}\text { Abordam o papel do estágio como } \\
\text { um processo inicial da prática que } \\
\text { culmina em transformação da } \\
\text { identidade profissional. }\end{array}$ \\
\hline $\begin{array}{l}\text { Yamamoto } \\
\text { e Cunha }\end{array}$ & 1998 & $\begin{array}{l}\text { O psicólogo em } \\
\text { hospitais de Natal: } \\
\text { uma caracterização } \\
\text { preliminar }\end{array}$ & $\begin{array}{l}\text { Artigo em } \\
\text { periódico }\end{array}$ & $\begin{array}{l}\text { Porto Alegre, } \\
\text { RS: revista } \\
\text { Psicologia: } \\
\text { Reflexão e } \\
\text { Crítica }\end{array}$ & $\begin{array}{l}\text { Destaca que a formação inicial } \\
\text { tem um viés clínico, além de } \\
\text { falhas na preparação para atuação } \\
\text { profissional, o que exige constante } \\
\text { aprimoramento. }\end{array}$ \\
\hline Melo-Silva & 1999 & $\begin{array}{l}\text { Estágio } \\
\text { profissionalizante em } \\
\text { orientação profissional: } \\
\text { experiência de } \\
\text { supervisão em um } \\
\text { curso de Psicologia }\end{array}$ & $\begin{array}{l}\text { Artigo em } \\
\text { periódico }\end{array}$ & $\begin{array}{l}\text { Florianópolis, } \\
\text { SC: Revista da } \\
\text { ABOP }\end{array}$ & $\begin{array}{l}\text { Descreve o funcionamento } \\
\text { de um estágio em orientação } \\
\text { profissional, no Curso de } \\
\text { Psicologia, e centra-se na } \\
\text { formação e qualificação do } \\
\text { psicólogo. }\end{array}$ \\
\hline Aguirre & 2000 & $\begin{array}{l}\text { A formação da atitude } \\
\text { clínica no estagiário de } \\
\text { Psicologia }\end{array}$ & $\begin{array}{l}\text { Artigo em } \\
\text { periódico }\end{array}$ & $\begin{array}{l}\text { São Paulo, } \\
\text { SP: Revista } \\
\text { Psicologia USP }\end{array}$ & $\begin{array}{l}\text { Discute o processo de ensino- } \\
\text { aprendizagem na formação do } \\
\text { psicólogo clínico na universidade. }\end{array}$ \\
\hline $\begin{array}{l}\text { Melo-Silva } \\
\text { e Santos }\end{array}$ & 2003 & $\begin{array}{l}\text { "Será que era isso } \\
\text { que eu queria?": a } \\
\text { formação acadêmica } \\
\text { em Psicologia na } \\
\text { perspectiva do aluno }\end{array}$ & $\begin{array}{l}\text { Capítulo de } \\
\text { livro }\end{array}$ & $\begin{array}{l}\text { São Paulo, SP: } \\
\text { Vetor }\end{array}$ & $\begin{array}{l}\text { Focaliza a formação acadêmica } \\
\text { em Psicologia e a responsabilidade } \\
\text { dos cursos em transmitirem a } \\
\text { imagem que o futuro psicólogo } \\
\text { elabora de sua profissão. }\end{array}$ \\
\hline $\begin{array}{l}\text { Ferreira } \\
\text { Neto e } \\
\text { Penna }\end{array}$ & 2006 & $\begin{array}{l}\text { Ética, clínica } \\
\text { e diretrizes: a } \\
\text { formação do } \\
\text { psicólogo em } \\
\text { tempos de } \\
\text { avaliação de curso }\end{array}$ & $\begin{array}{l}\text { Artigo em } \\
\text { periódico }\end{array}$ & $\begin{array}{l}\text { Maringá, PR: } \\
\text { Psicologia em } \\
\text { Estudo }\end{array}$ & $\begin{array}{l}\text { Discute a relação entre ética e } \\
\text { clínica no contexto da formação } \\
\text { universitária do psicólogo. } \\
\text { Apresenta a área clínica como } \\
\text { inflacionada nos currículos e como } \\
\text { isso tem influência na construção } \\
\text { da imagem do psicólogo. }\end{array}$ \\
\hline $\begin{array}{l}\text { Scorsolini- } \\
\text { Comin, } \\
\text { Souza e } \\
\text { Santos }\end{array}$ & 2008 & $\begin{array}{l}\text { Tornar-se psicólogo: } \\
\text { experiência de } \\
\text { estágio de Psico- } \\
\text { oncologia em equipe } \\
\text { multiprofissional de } \\
\text { saúde }\end{array}$ & $\begin{array}{l}\text { Artigo em } \\
\text { periódico }\end{array}$ & $\begin{array}{l}\text { São Paulo, SP: } \\
\text { Revista Brasileira } \\
\text { de Orientação } \\
\text { Profissional }\end{array}$ & $\begin{array}{l}\text { Discute a construção da } \\
\text { identidade profissional do } \\
\text { estagiário de Psicologia, a partir } \\
\text { de uma experiência em um } \\
\text { serviço público com pacientes } \\
\text { mastectomizadas. }\end{array}$ \\
\hline
\end{tabular}


A Tabela 4 apresenta a distribuição dos estudos relacionados à categoria 1. Construção da identidade profissional do psicólogo e à subcategoria 1.3. O exercício da profissão psicólogo ( $\mathrm{n}=$ 7). Foram reunidos nessa categoria os estudos de Sipoli (1991), Tescariolli (1999), Yamamoto, Câmara, Silva e Dantas, (2001), Santos (2002), Santos (2003), Krawulski (2004) e Corona (2004).

Tabela 4. Distribuição dos estudos referentes à subcategoria 1.3. O exercício da profissão psicólogo, segundo autor, ano de publicação, título, natureza da publicação, local/editora e síntese do estudo.

\begin{tabular}{|c|c|c|c|c|c|}
\hline Autor & $\begin{array}{c}\text { Ano de } \\
\text { publicação }\end{array}$ & Título & $\begin{array}{l}\text { Natureza da } \\
\text { publicação }\end{array}$ & Local/Editora & Síntese do estudo \\
\hline Sipoli & 1991 & $\begin{array}{l}\text { Negociação da } \\
\text { identidade profissional } \\
\text { do psicólogo em um } \\
\text { projeto multidisciplinar } \\
\text { de ação comunitária } \\
\text { rural }\end{array}$ & $\begin{array}{l}\text { Dissertação } \\
\text { de mestrado }\end{array}$ & $\begin{array}{l}\text { São Paulo, SP: } \\
\text { Programa de } \\
\text { Pós-Graduação em } \\
\text { Psicologia, Pontifícia } \\
\text { Universidade Católica } \\
\text { de São Paulo }\end{array}$ & $\begin{array}{l}\text { Diz respeito à questão da } \\
\text { identidade profissional do } \\
\text { psicólogo e visa a compreender } \\
\text { como o mesmo negocia } \\
\text { sua identidade profissional } \\
\text { quando não encontra rotinas } \\
\text { estabelecidas para sua atuação. }\end{array}$ \\
\hline Tescariolli & 1999 & $\begin{array}{l}\text { Identidade e profissão: } \\
\text { um estudo sobre } \\
\text { a identidade do } \\
\text { psicólogo professor } \\
\text { universitário e clínico }\end{array}$ & $\begin{array}{l}\text { Dissertação } \\
\text { de mestrado }\end{array}$ & $\begin{array}{l}\text { São Paulo, SP: } \\
\text { Programa de } \\
\text { Pós-Graduação em } \\
\text { Psicologia Social, } \\
\text { Universidade de São } \\
\text { Paulo }\end{array}$ & $\begin{array}{l}\text { Trata-se de um estudo sobre as } \\
\text { representações de psicólogos } \\
\text { professores universitários clínicos } \\
\text { acerca da identidade profissional } \\
\text { por meio do fazer e do ser } \\
\text { psicólogo. }\end{array}$ \\
\hline $\begin{array}{l}\text { Yamamoto } \\
\text { et al. }\end{array}$ & 2001 & $\begin{array}{l}\text { Espaços, práticas: o } \\
\text { que há de novo na } \\
\text { Psicologia do Rio } \\
\text { Grande do Norte? }\end{array}$ & $\begin{array}{l}\text { Artigo em } \\
\text { periódico }\end{array}$ & $\begin{array}{l}\text { Maringá, PR: revista } \\
\text { Psicologia em Estudo }\end{array}$ & $\begin{array}{l}\text { Apresenta ampliação das áreas } \\
\text { de atuação do psicólogo como } \\
\text { práticas emergentes; no entanto, } \\
\text { a prática dos profissionais nesses } \\
\text { novos espaços configura práticas } \\
\text { tradicionais. }\end{array}$ \\
\hline Santos & 2002 & $\begin{array}{l}\text { Aspectos identitários } \\
\text { do psicólogo no } \\
\text { serviço público de } \\
\text { saúde (1989-2000) }\end{array}$ & $\begin{array}{l}\text { Dissertação } \\
\text { de mestrado }\end{array}$ & $\begin{array}{l}\text { São Paulo, SP: } \\
\text { Programa de } \\
\text { Pós-Graduação } \\
\text { em Psicologia, } \\
\text { Universidade São } \\
\text { Marcos }\end{array}$ & $\begin{array}{l}\text { Aborda como foi sendo } \\
\text { possibilitado ao psicólogo manter } \\
\text { ou transformar sua identidade, } \\
\text { entendida como seu próprio } \\
\text { fazer ou prática cotidiana, } \\
\text { constituído pelas referências do } \\
\text { Sistema Conselhos de Psicologia } \\
\text { e pelas políticas de saúde pública } \\
\text { implantadas pelas diferentes } \\
\text { administrações da prefeitura } \\
\text { paulista. }\end{array}$ \\
\hline Santos & 2003 & $\begin{array}{l}\text { Profissão: } \\
\text { psicoterapeuta } \\
\text { - vicissitudes da } \\
\text { formação acadêmica } \\
\text { e da inserção no } \\
\text { mercado de trabalho }\end{array}$ & $\begin{array}{l}\text { Capítulo } \\
\text { de livro }\end{array}$ & São Paulo, SP: Vetor & $\begin{array}{l}\text { Analisa a trajetória profissional } \\
\text { construída por psicoterapeutas, } \\
\text { procurando detectar os fatores } \\
\text { que influenciaram sua atuação e } \\
\text { as escolhas quanto aos referenciais } \\
\text { teóricos e técnicos que orientam } \\
\text { as práticas. }\end{array}$ \\
\hline Krawulski & 2004 & $\begin{array}{l}\text { Construção da } \\
\text { identidade profissional } \\
\text { do psicólogo: vivendo } \\
\text { as metamorfoses do } \\
\text { caminho no exercício } \\
\text { cotidiano do trabalho }\end{array}$ & $\begin{array}{l}\text { Tese de } \\
\text { doutorado }\end{array}$ & $\begin{array}{l}\text { Florianópolis, } \\
\text { SC: Programa de } \\
\text { Pós-Graduação } \\
\text { em Ergonomia, } \\
\text { Universidade } \\
\text { Federal de Santa } \\
\text { Catarina }\end{array}$ & $\begin{array}{l}\text { Investiga a construção da } \\
\text { identidade do psicólogo, no } \\
\text { cotidiano de seu trabalho, as } \\
\text { vivências profissionais da trajetória } \\
\text { e o significado dessa trajetória } \\
\text { na construção da identidade } \\
\text { profissional. }\end{array}$ \\
\hline Corona & 2004 & $\begin{array}{l}\text { Trajetórias dos } \\
\text { professores de } \\
\text { Psicologia do Espírito } \\
\text { Santo: atuação e } \\
\text { identidade profissional. }\end{array}$ & $\begin{array}{l}\text { Dissertação } \\
\text { de mestrado }\end{array}$ & $\begin{array}{l}\text { Vitória, ES: } \\
\text { Programa de } \\
\text { Pós-Graduação } \\
\text { em Psicologia, } \\
\text { Universidade } \\
\text { Federal do Espírito } \\
\text { Santo }\end{array}$ & $\begin{array}{l}\text { Mostra como professores de } \\
\text { Psicologia de instituições privadas } \\
\text { de ensino superior do Estado } \\
\text { do Espírito Santo percebem } \\
\text { sua identidade profissional e } \\
\text { a relação dessa identidade na } \\
\text { representação da Psicologia. }\end{array}$ \\
\hline
\end{tabular}


Na categoria 2. Mudança de paradigma: do individual para o social, algumas considerações são feitas sobre os aspectos realçados nos estudos que propõem mudanças necessárias na identidade do psicólogo na sociedade brasileira, no que se refere à mudança do paradigma tradicional nas intervenções que priorizam o indivíduo, para uma abertura à perspectiva que valoriza o social.

A Tabela 5 apresenta a distribuição dos estudos relacionados à categoria 2. Mudança de paradigma: do individual para o social $(\mathrm{n}=8)$. Nessa categoria, foram reunidas as publicações de MartinBaró (1996), Freitas (1998), Bock, (1999), Contini (2000), Gioia-Martins e Rocha-Junior (2001), Dimenstein (2001), Praça e Novaes (2004) e Yamamoto (2007). Observa-se a predominância de estudos publicados em periódicos científicos.

Tabela 5. Distribuição dos estudos referentes à categoria 2. Mudança de paradigma: do individual para o social, segundo autor, ano de publicação, título, natureza da publicação, local/editora e síntese do estudo

\begin{tabular}{|c|c|c|c|c|c|}
\hline Autor & $\begin{array}{l}\text { Ano de } \\
\text { publicação }\end{array}$ & Título & $\begin{array}{c}\text { Natureza da } \\
\text { publicação }\end{array}$ & Local/Editora & Síntese do estudo \\
\hline $\begin{array}{l}\text { Martin- } \\
\text { Baró }\end{array}$ & 1996 & $\begin{array}{l}\text { O papel do } \\
\text { psicólogo }\end{array}$ & $\begin{array}{l}\text { Artigo em } \\
\text { periódico }\end{array}$ & $\begin{array}{l}\text { Natal, RN: revista } \\
\text { Estudos de Psicologia }\end{array}$ & $\begin{array}{l}\text { Propõe que o papel do } \\
\text { psicólogo é conscientizar } \\
\text { as pessoas a superarem sua } \\
\text { identidade alienada. }\end{array}$ \\
\hline Freitas & 1999 & $\begin{array}{l}\text { Inserção na } \\
\text { comunidade } \\
\text { e análise de } \\
\text { necessidades: } \\
\text { reflexões sobre } \\
\text { a prática do } \\
\text { psicólogo }\end{array}$ & $\begin{array}{l}\text { Artigo em } \\
\text { periódico }\end{array}$ & $\begin{array}{l}\text { Porto Alegre, RS: } \\
\text { revista Psicologia: } \\
\text { Reflexão e Crítica }\end{array}$ & $\begin{array}{l}\text { Analisa a inserção do psicólogo } \\
\text { na comunidade, os objetivos } \\
\text { que orientam sua prática e os } \\
\text { reflexos na construção de sua } \\
\text { identidade. }\end{array}$ \\
\hline Bock & 1999 & $\begin{array}{l}\text { A Psicologia a } \\
\text { caminho do novo } \\
\text { século: identidade } \\
\text { profissional e } \\
\text { compromisso } \\
\text { social }\end{array}$ & $\begin{array}{l}\text { Artigo em } \\
\text { periódico }\end{array}$ & $\begin{array}{l}\text { Natal, RN: revista } \\
\text { Estudos de Psicologia }\end{array}$ & $\begin{array}{l}\text { Defende a identidade } \\
\text { dos psicólogos como um } \\
\text { movimento permanente } \\
\text { de transformação, em uma } \\
\text { perspectiva social. }\end{array}$ \\
\hline Contini & 2000 & $\begin{array}{l}\text { Discutindo o } \\
\text { conceito de } \\
\text { promoção de } \\
\text { saúde no trabalho } \\
\text { do psicólogo } \\
\text { que atua em } \\
\text { educação }\end{array}$ & $\begin{array}{l}\text { Artigo em } \\
\text { periódico }\end{array}$ & $\begin{array}{l}\text { Brasilia, DF: revista } \\
\text { Psicologia: Ciência e } \\
\text { Profissão }\end{array}$ & $\begin{array}{l}\text { Discute o conceito de } \\
\text { promoção de saúde no } \\
\text { trabalho do psicólogo que } \\
\text { atua em educação e as } \\
\text { ações que enfatizam o } \\
\text { compromisso ético e político } \\
\text { na construção da cidadania } \\
\text { da população atendida. }\end{array}$ \\
\hline $\begin{array}{l}\text { Gioia- } \\
\text { Martins e } \\
\text { Rocha- } \\
\text { Junior }\end{array}$ & 2001 & $\begin{array}{l}\text { Psicologia da } \\
\text { saúde e o novo } \\
\text { paradigma: novo } \\
\text { paradigma? }\end{array}$ & $\begin{array}{l}\text { Artigo em } \\
\text { periódico }\end{array}$ & $\begin{array}{l}\text { São Paulo, SP: revista } \\
\text { Psicologia: Teoria e } \\
\text { Prática }\end{array}$ & $\begin{array}{l}\text { Reflete sobre o modelo de } \\
\text { profissional de Psicologia } \\
\text { no Brasil e o papel do } \\
\text { psicólogo e a identidade } \\
\text { profissional, em uma visão } \\
\text { biopsicossocial. }\end{array}$ \\
\hline Dimenstein & 2001 & $\begin{array}{l}\text { O psicólogo e } \\
\text { o compromisso } \\
\text { social no contexto } \\
\text { da saúde coletiva }\end{array}$ & $\begin{array}{l}\text { Artigo em } \\
\text { periódico }\end{array}$ & $\begin{array}{l}\text { Maringá, PR:revista } \\
\text { Psicologia em Estudo }\end{array}$ & $\begin{array}{l}\text { Trata da mudança no } \\
\text { perfil profissional em } \\
\text { saúde, a partir de um } \\
\text { compromisso social } \\
\text { assumido e desejado } \\
\text { para a categoria da } \\
\text { Psicologia. }\end{array}$ \\
\hline $\begin{array}{l}\text { Praça e } \\
\text { Novaes }\end{array}$ & 2004 & $\begin{array}{l}\text { A representação } \\
\text { social do trabalho } \\
\text { do psicólogo }\end{array}$ & $\begin{array}{l}\text { Artigo em } \\
\text { periódico }\end{array}$ & $\begin{array}{l}\text { Brasilia, DF: revista } \\
\text { Psicologia: Ciência e } \\
\text { Profissão }\end{array}$ & $\begin{array}{l}\text { Esse trabalho buscou } \\
\text { conhecer as representações } \\
\text { sociais da Psicologia e do } \\
\text { trabalho do psicólogo. }\end{array}$ \\
\hline
\end{tabular}


Continuação tabela 5

\begin{tabular}{|c|c|c|c|c|c|}
\hline Autor & $\begin{array}{l}\text { Ano de } \\
\text { publicação }\end{array}$ & Título & $\begin{array}{l}\text { Natureza da } \\
\text { publicação }\end{array}$ & Local/Editora & Síntese do estudo \\
\hline Yamamoto & 2007 & $\begin{array}{l}\text { Políticas sociais, } \\
\text { terceiro setor e } \\
\text { compromisso } \\
\text { social: } \\
\text { perspectivas e } \\
\text { limites do trabalho } \\
\text { do psicólogo }\end{array}$ & $\begin{array}{l}\text { Artigo em } \\
\text { periódico }\end{array}$ & $\begin{array}{l}\text { Porto Alegre, RS: revista } \\
\text { Psicologia e Sociedade }\end{array}$ & $\begin{array}{l}\text { Discute as possibilidades e os } \\
\text { limites do trabalho do psicólogo } \\
\text { no campo } \\
\text { do bem-estar social/público e } \\
\text { no terceiro setor como contexto } \\
\text { para discussão do compromisso } \\
\text { social do psicólogo. }\end{array}$ \\
\hline
\end{tabular}

É importante destacar que a distribuição dos estudos em categorias cumpre a função de sistematizar os dados como ponto de partida para as reflexões acerca da produção do conhecimento. De certa forma, trata-se de uma organização didática, visando a dar ao leitor uma visão mais apurada a respeito dos estudos que constituíram o corpus de análise. É evidente que um mesmo estudo poderia ser inserido em mais de uma categoria; um estudo sobre o exercício da profissão, por exemplo, pode focalizar também a formação ou a mudança de paradigmas na área. Porém, para efeito de análise, cada estudo foi inserido em apenas uma categoria, a que corresponde ao objetivo principal da investigação. As publicações objeto de estudo também foram utilizadas como referenciais para discutir os dados.

\section{Discussão}

A partir dos estudos sistematizados nas Tabelas 2, 3, 4, e 5 apresentadas anteriormente, os dados foram analisados, o que possibilita refletir sobre a produção do conhecimento em cada categoria e subcategoria.

\section{Categoria 1.}

\section{Construção da identidade profissional do psicólogo}

\subsection{A escolha da Psicologia como profissão}

A literatura revela que a escolha pela profissão de psicólogo está integrada às expectativas e idealizações sobre o curso e o papel profissional, configurando uma possibilidade de compreensão do ser humano (Krawulski \& Patrício, 2005; Krawulski, 2004; Magalhães, 2001). As questões da identidade pessoal, ocupacional e vocacional são inerentes à escolha profissional do psicólogo, como apontou Abreu Filho (2000), dentro de um aporte teórico psicanalítico kleiniano.

A escolha da Psicologia como profissão relaciona-se também a elementos como história pessoal e/ou características pessoais dos psicólogos, habilidades ou capacidades que predispunham ao exercício dessa profissão, como disponibilidade para ouvir, aconselhar e mediar conflitos, como também se considerarem pessoas calmas, pacientes e tranquilas (Magalhães, 2001). A possibilidade de conhecer o ser humano e ajudá-lo caracteriza uma motivação central, além do desejo de auto- ajuda e autoconhecimento (Krawulski \& Patrício, 2005; Krawulski, 2004). 
Segundo Melo-Silva e Santos (2003), a formação em Psicologia é, em grande parte, responsável pela imagem que o psicólogo elabora de sua profissão e de seu campo específico de competência.
Pode-se "descrever a escolha profissional como um processo que visa a aumentar ao longo da vida profissional a adequação de si mesmo e o seu ambiente", como apontam Guichard e Huteau (2002, p. 182), o que remete à teoria desenvolvimentista de Super 1980. Conhecer o ser humano seria uma forma de o psicólogo se conhecer?

Ser psicólogo significaria ajudar as pessoas, sendo esse o principal propósito da profissão (Krawulski, 2004; Magalhães, 2001). Para tanto, estudantes de Psicologia e profissionais buscam exercer um trabalho de relação direta com o ser humano, uma relação interpessoal específica, traduzida em interações que permitam conhecer e compreender sua essência e seu comportamento (Krawulski, 2004).

O processo de construção da identidade profissional começa a ser gestado quando tomam forma o interesse e o desejo de ter a Psicologia como profissão, a partir das primeiras identificações e de algumas representações sobre o exercício da atividade do psicólogo, presentes na situação de escolha profissional, que constituem uma base importante para os primeiros significados atribuídos ao serpsicólogo (Krawulski \& Patrício, 2005). Esse processo será continuado na graduação.

\subsection{A formação acadêmica em Psicologia}

A construção da identidade do psicólogo enquanto profissional ocorre por meio do desenvolvimento de uma atitude, que se inicia na graduação, como apontaram Aguirre et al. (2000). Para eles, a construção da identidade profissional do futuro psicólogo envolve um complexo conjunto de experiências internalizadas, que abrange desde a concepção de mundo e a adoção de valores até a exteriorização em escolhas e comportamentos. A compreensão de como se processa o trabalho do psicólogo, associada à compreensão do porquê se processa dessa forma, alicerça a formação dessa identidade.

Segundo Melo-Silva e Santos (2003), a formação em Psicologia é, em grande parte, responsável pela imagem que o psicólogo elabora de sua profissão e de seu campo específico de competência. O papel do psicólogo é geralmente idealizado pelos alunos na graduação, estando repleto de fantasias e expectativas quanto à atuação desse profissional (Aguirre et al., 2000; Bohoslavsky, 1991; Melo-Silva \& Reis, 1997). A imagem do psicólogo é impregnada de estereótipos e representações sociais que, muitas vezes, distorcem a realidade.

Para além das estereotipias, a atividade prática do psicólogo em formação também influencia a elaboração das identidades, e para tal contribuem os estágios. A literatura mostra a importância do estágio profissionalizante, o papel da supervisão durante a graduação (Aguirre et al., 2000; Melo-Silva, 1999; Vilela, 1996) e da formação complementar como importantes para a consolidação das identidades. A vivência de estágio e o envolvimento com a atuação profissional são relevantes como elementos constitutivos da identidade profissional do psicólogo, como destacaram Melo-Silva e Reis (1997) e Scorsolini-Comin, Souza e Santos (2008). Além da vivência de estágio, a supervisão é situada como importante atividade para a reflexão e a construção de uma identidade profissional por diferentes autores.

É por meio dos estágios na graduação e da supervisão que recebe dos professores que o estudante aprende realmente a ser psicólogo. 
Vilela (1996) critica o modelo de formação do psicólogo que é dirigido prioritariamente para as disciplinas teóricas, e enfoca o estágio e a supervisão, vistos como a parte positiva da formação, em que verdadeiramente se aprende a ser psicólogo.

Se, por um lado, os estágios são bem vistos, por outro, os currículos são compreendidos como limitadores. Os currículos dos cursos de ensino superior são apontados por Ferreira Neto e Penna (2006) como grandes contribuidores de uma imagem de profissional com ênfase no modelo de atuação clínica. Nesse sentido, Yamamoto (1998) já havia afirmado que a formação inicial do psicólogo tinha um viés clínico, além de deficiências na preparação para atuação profissional. Por sua vez, dez anos depois do estudo de Yamamoto e Pires (2008) também aponta problemas na graduação, destacando o caráter excessivamente teórico na formação em Psicologia e a necessidade de a prática profissionalizante ser antecipada no currículo.

A formação, seja boa ou insuficiente, é que permitirá ao psicólogo a transição da universidade para o trabalho. E essa transição poderá ser tranquila e/ou problemática. Olenscki e Salibe (1998) afirmam que a passagem do papel de aluno para o de profissional traz consigo um luto, deixando para traz uma certa dependência e postura, adquirida na formação acadêmica, e o profissional passa, então, a traçar um novo caminho a ser percorrido e construído. As autoras enfatizam o papel de estagiário, nos últimos anos da graduação, como um processo de transformação, de amadurecimento da identidade profissional, que vai se constituindo nos primeiros anos da prática.

Na trajetória profissional, novos desafios estão colocados, havendo a necessidade de uma busca por aprimoramento, já que a exigência de novos campos e áreas de atuação requer a superação dos papéis tradicionais e a revisão dos referenciais da Psicologia e da formação acadêmica.

\subsection{O exercício da profissão psicólogo}

De acordo com Praça e Novaes (2004), o fazer do psicólogo é efeito, em grande parte, da formação que o profissional recebe. A percepção da experiência como aluno contribui de modo significativo para a atribuição de significados ao processo do vir-aser psicólogo, o que se reflete na constituição da identidade profissional (Krawulski \& Patrício, 2005; Krawulski, 2004; Santos \& Melo-Silva, 2003). Uma vez graduados, muitos buscam a inserção no mercado de trabalho por meio de cursos, supervisão e psicoterapia pessoal (Krawulski, 2004; MeloSilva, 1999; Melo-Silva \& Reis, 1997; Santos, 2003), que auxiliam na construção da sua identidade profissional.

A identidade profissional em Psicologia, segundo Krawulski (2004), pode ser definida como uma construção social, formada a partir do conjunto das experiências do percurso profissional, embora o pontapé inicial tenha sido a formação acadêmica. Identidade profissional seria aquilo que identifica e apresenta o profissional, o modo como ele se mostra, algo que vai sendo construído com o tempo e com as atividades de trabalho, e que conduz à incorporação de um papel.

Considera-se que, na construção da identidade profissional, entram componentes da experiência pessoal de vida, além das experiências de trabalho. Como afirma Krawulski (2004), essa construção "não tem data para ficar pronta", e sua dinâmica 
permite que sempre se possa buscar outras possibilidades, modificando o conjunto, em um movimento de "pensar e repensar constante" sobre a profissão (p. 118).

Embora seja reconhecida a importância da formação acadêmica, dos estágios, da supervisão e da própria experiência pessoal como componentes de base da identidade profissional, esta vai sendo construída e consolidada na prática do exercício da profissão através das possibilidades e limitações oferecidas pela trajetória e pelo cotidiano de trabalho do psicólogo (Aguirre et al., 2000; Krawulski, 2004; Krawulski \& Patrício, 2005; Melo-Silva, 1999; Melo-Silva \& Santos, 2003).

Gradualmente, essas vivências no cotidiano do trabalho vão conduzindo ao desenvolvimento de uma postura profissional, elemento essencial para a definição de uma identidade profissional. Santos (2002) e Corona (2004) entendem a identidade do psicólogo como seu próprio fazer ou prática cotidiana, e destacam que tais práticas, saberes e o processo de formação incidem no modo como os psicólogos trabalham e também no modo como concebem a si mesmos.

Krawulski (2004) ressalta que o processo de construção da identidade profissional do psicólogo pode ser compreendido na perspectiva do desenvolvimento e da transformação do profissional pelo seu fazer. Essa transformação se expressa no modo como a profissão impregna a vida pessoal dos psicólogos, produzindo modificações em sua percepção de mundo, em seus valores e na própria postura diante da vida. Esse processo envolve um movimento constante de "construir-desconstruir-reconstruir significados da profissão, e que implica reconhecer e assimilar as 'metamorfoses' ao longo do percurso profissional" (Krawulski, 2004, p. 9). Para vir-a-ser psicólogo, não basta adquirir as habilidades associadas à carreira, mas é necessária também a construção de uma identidade de carreira.

De acordo com o estudo feito por Sipoli (1991), a identidade profissional do psicólogo é frágil, mal delimitada e se encontra em processo de construção, e há necessidade de conhecimentos especializados para atuar em trabalhos novos. A autora destaca ainda que a representação da profissão precisa ser mais realista e contextualizada, necessita de reformulação nos cursos e currículos de Psicologia e da produção de pesquisas que ampliem a área de conhecimentos e técnicas do exercício profissional. Cumpre refletir se a conclusão da referida autora ainda se aplica na atualidade, uma vez que o estudo tem quase duas décadas, e se há semelhanças ou diferenças em relação a outras categorias profissionais. Por sua vez, Tescariolli (1999) procurou compreender como psicólogos, na função de professores universitários e clínicos, se representam e ampliam a visão da realidade de acordo com as demandas. A autora aponta uma atuação dos psicólogos muito pouco voltada para os problemas sociais.

Três anos depois, Yamamoto et al. (2001) focalizam a ampliação dos espaços profissionais ocupados pelo psicólogo desde a regulamentação da Psicologia como profissão, e apresentam áreas de atuação do psicólogo como emergentes, mostrando que a atuação dos profissionais nos novos espaços configura práticas tradicionais.

A trajetória profissional construída por psicoterapeutas foi investigada por Santos 
(2003), que procurou detectar fatores que influenciaram a atuação dos participantes e as suas escolhas quanto aos referenciais teóricos nos quais se especializaram. O autor destaca que esses elementos constituintes da identidade do psicólogo têm seus alicerces na formação acadêmica. A análise dos dados, porém, permite concluir que a trajetória profissional, especificamente de sua amostra, é um processo em aberto, inconcluso, um vir-a-ser psicoterapeuta. Em analogia a esse estudo, pode-se afirmar que ser psicólogo, de um modo geral, consiste em uma busca constante de contornos identitários.

2. Mudança de paradigma: do individual para o social

No processo de mutação das carreiras, notadamente na Psicologia, as mudanças de paradigma, em um dado momento, afetam a identidade profissional. Dimenstein (2000) afirma que a difusão da psicanálise no século XX produziu a representação de um sujeito psicológico - particular, individualista, dotado de uma interioridade que lhe é singular - e de práticas baseadas nesse modo de subjetividade - singular a cada sujeito - que culminaram por definir a identidade e a cultura profissional do psicólogo. A autora ainda coloca que

algumas características da formação e da identidade profissional do psicólogo no Brasil têm relação direta com esse processo de hegemonização do ideário individualista, de intensa difusão das teorias e práticas psi - mediatizada pelos especialistas da área - e de um modelo específico de subjetividade. (Dimenstein, 2000, p. 100)

A formação do psicólogo está calcada em um modelo clínico, sustentado por teorias que têm seu foco voltado para a descrição e o tratamento de comportamentos patológicos, como apontou Contini (2000). Essa situação tem contribuindo para a consolidação da identidade do psicólogo marcada por um caráter exclusivamente terapêutico, o que dificulta a construção de um outro profissional que possa atender diferentes situações, como as institucionais e as comunitárias.

Segundo Dimenstein (2001),

\begin{abstract}
do ponto de vista do processo de trabalho, entendemos que os psicólogos precisam incorporar uma nova concepção de prática profissional, associada ao processo de cidadanização, de construção de sujeitos com capacidade de ação e de proposição. Isso implica romper o corporativismo, as práticas isoladas e a identidade profissional hegemônica vinculada à do psicoterapeuta. Notamos que o modelo clínico da psicoterapia individual ainda é a forma de trabalho predominante entre os profissionais no setor público, predominância muitas vezes atribuída ao desejo da clientela ou da instituição. (p. 62)
\end{abstract}

Historicamente, uma das atribuições do psicólogo consiste em adequar, ajustar e adaptar indivíduos. Nesse processo, alguns dos procedimentos utilizados incluem a aplicação de testes. Diagnosticar consiste em uma importante função do psicólogo. Tal função auxilia na definição da identidade profissional do psicólogo, uma vez que os instrumentos de avaliação psicológica são de uso exclusivo do psicólogo. Por outro lado, a intervenção pautada fundamentalmente em testes individuais denota a ausência da dimensão social na concepção da Psicologia sobre seu objeto de estudo, como destacam Praça e Novaes (2004). Os autores discutem até que ponto as representações sociais do psicólogo refletem uma visão que inclui a dimensão político-social do seu papel, ou seja, se é um profissional crítico no contexto no qual está inserida sua intervenção ou 
se é um profissional comprometido com a adaptação social, legitimando a imagem do psicólogo na sociedade.

No Brasil, nas últimas décadas, a profissão Psicologia tem sido chamada a ocupar novos espaços e a desenvolver trabalhos e/ou atividades que até então eram pouco frequentes (Freitas, 1998). Trata-se da possibilidade de construção de uma nova identidade do psicólogo brasileiro, que dá ênfase ao compromisso social da profissão (Bock, 1999; Freitas, 1998; Gioia-Martins \& Rocha-Junior, 2001; Martin-Baró, 1996).

De acordo com Yamamoto (2007),

\begin{abstract}
A exigência posta no debate atual sobre a profissão, de atuar com compromisso social, certamente não é nova. As intermináveis discussões sobre a 'função social do psicólogo' que acompanharam o desenvolvimento da profissão até anos recentes - quando então foi substituída pela demanda por 'compromisso social' - são testemunhas disso. (p. 30)
\end{abstract}

A literatura aponta um movimento de profunda reflexão sobre o papel do psicólogo na sociedade brasileira, enfatizando a necessidade de reformulação no processo de formação de psicólogos e nos paradigmas adotados para o desenvolvimento de seu trabalho (Bock, 1999; Freitas, 1998; Gioia-Martins \& Rocha-Junior, 2001; Lane, 1999).

A Psicologia, enquanto ciência e profissão, encontra-se em um momento de reflexão, cuja finalidade é redefinir o papel do psicólogo na sociedade, como apontou Bock (1999). A autora defende a ideia de uma identidade para os psicólogos que seja "movimento e transformação", porque é reflexo do vínculo que a Psicologia deve manter com a sociedade, que está sempre em movimento, vínculo esse de compromisso com as necessidades e as demandas da maioria da população brasileira.

O modelo de profissional de Psicologia no Brasil foi se transformando a partir das necessidades da sociedade. Gioia-Martins e Rocha-Junior (2001) propõem, como alternativa para romper a imagem tradicional da Psicologia, uma formação - generalista e teórico-prática - que habilite o profissional a realizar uma análise crítica da realidade brasileira e o capacite a detectar alternativas de intervenção, para que ele seja capaz de acompanhar e responder às demandas sociais e políticas da população brasileira, buscando melhoria na qualidade de vida.

Corroborando essas colocações, Bock (1999) afirma que assumir um compromisso social em Psicologia é estar voltado para uma intervenção crítica e transformadora de nossas condições de vida, é estar comprometido com a crítica dessa realidade a partir da perspectiva enquanto ciência e profissão. Nessa direção, Martin-Baró (1996) propõe uma mudança no fazer teórico-prático do psicólogo, uma quebra no paradigma que acompanha a Psicologia ao longo de sua história.

O papel do psicólogo dentro dessa nova concepção é o de um agente conscientizador que deve ajudar as pessoas a superarem sua identidade alienada, pessoal e social, ao transformar as condições sociais do seu contexto. Considerando a perspectiva histórico-social de ser humano, em que o homem transforma a sociedade ao mesmo tempo em que é transformado por ela, o autor pressupõe mudanças também na própria identidade profissional do psicólogo (Ciampa, 1999; Lane, 1999; Martin-Baró, 1996).

Bock (1999) afirma que é importante considerar que a identidade se encontra em constante 
movimento e metamorfose, acompanhando as transformações da realidade. No entanto, a identidade profissional do psicólogo reflete, ainda hoje, a prática que a Psicologia tem construído ao longo de sua história - elitista e restrita a demandas específicas da sociedade. Para a autora, construir uma profissão identificada com as necessidades da maioria da população brasileira, dadas as condições de vida que possui, constitui um desafio para o psicólogo no século XXI.

\section{Considerações finais}

A partir dos estudos encontrados na literatura brasileira acerca da construção da identidade profissional do psicólogo, é possível tecer algumas considerações. A construção da identidade profissional do psicólogo, segundo a literatura focalizada, é um conjunto integrado de fatores pessoais e de formação profissional que passa pela questão da escolha da Psicologia como profissão e o significado de ser psicólogo, a formação acadêmica e a vivência como profissional.

Em relação à formação acadêmica, observa-se a necessidade de mudanças nos parâmetros curriculares dos cursos de Psicologia, como apontadas desde a década de 90 (AnconaLopez, 2005). Observa-se, porém, um movimento recente na Psicologia, a partir da década de 1990, também período da divulgação dos estudos analisados, que trata da necessidade de mudança de paradigma como ciência e profissão no que se refere a uma quebra da perspectiva tradicional que prioriza o indivíduo. Tais mudanças, indubitavelmente, afetarão a identidade profissional do psicólogo.

Diversos resultados apresentados no presente estudo corroboram a idéia de situar a profissão Psicologia em uma perspectiva social, consideram a necessidade de contextualizar a práxis psicológica com a realidade brasileira, enfatizando o compromisso social da categoria. Tais discussões, que a literatura aponta em relação à construção de uma identidade profissional para o psicólogo, abarcam questões tanto de ordem tanto pessoal quanto profissional, ou seja, as combinações de diferentes e complementares papéis. Os estudos mostram um conceito de identidade profissional que não pode ser dissociado da identidade pessoal do sujeito, visto que o trabalho é uma dimensão que constitui o ser humano. "A carreira deve ser vista como uma relação que conecta vida pessoal e trabalho, e o planejamento da carreira deve significar o mesmo que planejamento de vida, o que se torna mais uma questão de administração de vida" (Jenschke, 2003, p. 40). Por outro lado, quando se trata de identidade profissional, deve-se levar em conta o psicólogo brasileiro como ser-trabalhador, inserido num contexto social, econômico, cultural e educacional.

Dessa forma, as mudanças em processo na carreira de Psicologia, nas práticas, nos saberes, na formação, incidem no modo de trabalhar e no modo como os psicólogos percebem a si mesmos. É possível pensar, então, na construção da identidade profissional do psicólogo em uma perspectiva de constante movimento, como apontado por vários autores. A diversidade de métodos e práticas da Psicologia e a singularidade das trajetórias pessoais contribuem para que cada ser-psicólogo, nessa construção da identidade como profissional, se constitua conforme o envolvimento com a atuação e como papel de psicólogo na sociedade brasileira.

Nesse sentido, se a identidade é entendida como movimento, a identidade profissional deve ser entendida da mesma forma, sendo que nunca estará acabada, mas em um constante processo de transformação e 
mudança. Assim, a identidade profissional do psicólogo brasileiro reflete a escolha, a formação, a prática e a busca incessante que acompanha a sociedade no sentido de atender as demandas sociais pertinentes, e não apenas as necessidades individuais.

As novas Diretrizes Curriculares Nacionais para os Cursos de Graduação em Psicologia (Brasil, 2004), amplamente debatidas nas instituições representativas da categoria e nos órgãos oficiais, propõem mudanças de paradigmas. "As diretrizes são claras quando propõem o compromisso do psicólogo de atuar em diferentes contextos considerando as necessidades sociais, os direitos humanos, tendo em vista a promoção da qualidade de vida dos indivíduos, grupos, organizações e comunidades (Art. 3, inciso "e") (AnconaLopez, 2005, p. 93).

A identidade profissional do psicólogo brasileiro acompanha, assim, o movimento da Psicologia no País, sua afirmação como profissão, a construção do conhecimento científico e técnico nas diversas áreas de atuação e a busca por espaço no mercado de trabalho. Uma identidade sempre em movimento reforça a necessidade de constantes estudos sobre a identidade profissional do psicólogo, de forma a manter a literatura nacional sempre atualizada em relação aos estudos pertinentes à Psicologia como profissão. Tais estudos compreendem uma busca teórica para a dimensão pessoal da Psicologia, o que diz respeito a cada profissional, independentemente de seu campo de atuação, de seus posicionamentos ideológicos. Assim, será possível compreender cada vez mais a permanência e a unicidade assim como a transformação e a multiplicidade de saberes, formações e práticas profissionais no contexto da Psicologia.

Finalizando, cabe destacar que, para que ocorram mudanças efetivas na profissão do psicólogo com vistas a um maior compromisso social, é necessário haver, também, políticas públicas de oferta de serviços psicológicos públicos e/ou privados, porém qualificados; assim, indubitavelmente, haverá mudança na carreira para atender as necessidades da maioria da população, pois também existirão espaços de trabalho em diferentes cenários e contextos para os psicólogos atuarem. É nessa direção que o Fórum de Entidades Nacionais da Área da Psicologia tem trabalhado, porém os resultados dessas ações dependem da efetiva participação do coletivo e de cada um dos psicólogos junto às instituições e aos que decidem as políticas públicas. 


\section{Sheila Maria Mazer}

Psicóloga. Mestre em Psicologia pelo Programa de Pós-Graduação da Faculdade de Filosofia, Ciências e Letras de Ribeirão Preto - Universidade de São Paulo, Ribeirão Preto, SP - Brasil.

E-mail: sheilamazer@hotmail.com

\section{Lucy Leal Melo-Silva}

Doutora em Psicologia, pesquisadora CNPq, professora da graduação e pós-graduação do Departamento de Psicologia e Educação, da Faculdade de Filosofia, Ciências e Letras de Ribeirão Preto - Universidade de São Paulo, Ribeirão Preto, SP - Brasil.

E-mail: lucileal@ffclrp.usp.br

Endereço para envio de correspondência:

Av. Bandeirantes, 3900 - Monte Alegre - Ribeirão Preto, SP - Brasil - CEP 14040-901.

Recebido 11/11/2008, 1a Reformulação 28/04/2009, Aprovado 13/6/2009.

\section{Referências}

Abreu Filho, A. G. (2000). Identidade: a questão da identidade profissional do psicólogo. Revista Psic, 1(2), 12-16.

Aguirre, A. M. B., Herzberg, E., Pinto, E. B., Becker, E., Carmo, H. M. S., \& Santiago, M. D. E. (2000). A formação da atitude clínica no estagiário de psicologia. Psicologia USP, 11(1), 49-62.

Ancona-Lopez, M. (2005). Considerações sobre as diretrizes curriculares nacionais para os cursos de Psicologia. In L. L. Melo-Silva, M. A. Santos \& C. P. Simon, Formação em Psicologia: serviços escola em debate. São Paulo: Vetor.

Bock, A. M. B. (1999). A Psicologia a caminho do novo século: identidade profissional e compromisso social. Estudos de Psicologia, 4(2), 315-329.

Bohoslavsky, R. (1991). A identidade profissional do orientador vocacional. In R. Bohoslavsky, Orientação vocacional: a estratégia clínica (pp. 173-201). São Paulo: Martins Fontes. (Trabalho original publicado em 1971)
Brasil. Conselho Nacional de Educação. Câmara de Educação Superior (2004). Resolução n. 8 de 7 de maio de 2004. Institui as Diretrizes Curriculares Nacionais para os Cursos de Graduação em Psicologia. Diário Oficial da União, (Seção 1), pp. 16-17.

Ciampa, A. C. (1999). Identidade. In S. T. M. Lane \& W. Codo (Eds.), Psicologia social: o homem em movimento (pp. 58-77). São Paulo: Brasiliense.

Contini, M. L. J. (2000). Discutindo o conceito de promoção de saúde no trabalho do psicólogo que atua em educação. Psicologia: Ciência e Profissão, 20(2), 46-58.

Corona, C. R. (2004). Trajetórias dos professores de psicologia do Espírito Santo: atuação e identidade profissional. Dissertação de Mestrado, Programa de Pós-Graduação em Psicologia, Universidade Federal do Espírito Santo, Vitória.

Dimenstein, M. (2000). A cultura profissional do psicólogo e o ideário individualista: implicações para a prática no campo da assistência pública à saúde. Estudos de Psicologia, 5(1), 95-121. 
Dimenstein, M. (2001). O psicólogo e o compromisso social no contexto da saúde coletiva. Psicologia em Estudo, 6(2), 57-63.

Erikson, E. H. (1987). Identidade: juventude e crise (2a ed., Á. Cabral, trad.). Rio de Janeiro: Guanabara.

Ferreira, N. S. A. (2002). As pesquisas denominadas estado da arte. Educação e Sociedade, 23(79), 257-272.

Ferreira Neto, J. L., \& Penna, L. M. D. (2006). Ética, clínica e diretrizes: a formação do psicólogo em tempos de avaliação de cursos. Psicologia em Estudo, 11(2), 381-390.

Figueiredo, L. C. (1993). Sob o signo da multiplicidade. Estudos de Psicologia, 10(1), 11-19.

Freitas, M. F. Q. (1998). Inserção na comunidade e análise de necessidades: reflexões sobre a prática do psicólogo. Psicologia: Reflexão e Crítica, 11(1), 175-189.

Galindo, W. C. M. (2004). A construção da identidade profissional docente. Psicologia: Ciência e Profissão, 24(2), 14-23.

Gioia-Martins, D., \& Rocha-Junior, A. (2001). Psicologia da saúde e o novo paradigma: novo paradigma? Psicologia: Teoria e Prática, 3(1), 35-42.

Guichard, J., \& Huteau, M. (2002). Psicologia da orientação. Lisboa: Instituto Piaget. (Trabalho original publicado em 2001)

Jenschke, B. (2003). A cooperação internacional: desafios e necessidades da orientação e do aconselhamento em face das mudanças mundiais no trabalho e na sociedade. Revista Brasileira de Orientação Profissional, 4(1/2), 35-55.

Krawulski, E. (2004). Construção da identidade profissional do psicólogo: vivendo as metamorfoses do caminho no exercício cotidiano do trabalho. Tese de Doutorado, Programa de PósGraduação em Ergonomia, Universidade Federal de Santa Catarina, Florianópolis.

Krawulski, E., \& Patrício, Z. M. (2005). Porque pessoas escolhem a psicologia como profissão? In M. C. P. Lassance (Ed.), Intervenção e compromisso social: Vol. 2. Orientação profissional: teoria e técnica (pp. 323-336). São Paulo: Vetor.

Lane, S. T. M. (1999). A psicologia social e uma nova concepção de homem para a psicologia. In S. T. M. Lane \& W. Codo (Eds.), Psicologia social: o homem em movimento (pp. 10-19). São Paulo: Brasiliense.

Luna, I. N. (2003). Realização pessoal e realização coletiva: a responsabilidade da orientação profissional na construção da identidade profissional. In L. L. Melo-Silva (Ed.), Arquitetura de uma ocupação (pp. 91-96). São Paulo: Vetor.

Magalhães, M. O. (2001). "Eu quero ajudar as pessoas": a escolha vocacional da psicologia. In Associação Brasileira de Orientação Profissional (Ed.), Anais do Simpósio Brasileiro de Orientação Vocacional \& Ocupacional, 4 (p. 189). São Paulo: ABOP.

Martin-Baró, I. (1996). O papel do psicólogo. Estudos de Psicologia, 3(1), 7-27.

Melo-Silva, L. L. (1999). Estágio profissionalizante em orientação profissional: experiência de supervisão em um curso de psicologia. Revista Brasileira de Orientação Profissional, 3(1), 119-135.

Melo-Silva, L. L., \& Reis, V. A B. (1997). A identidade profissional em estudantes do curso de psicologia: intervenção através da técnica de grupo operativo. In Associação Brasileira de Orientação Profissional (Ed.), Anais do Simpósio Brasileiro de Orientação Vocacional/ Profissional, 3, (pp. 57-65). Canoas, RS: ABOP.

Melo-Silva, L. L., \& Santos, M. A. (2003). "Será que era isso que eu queria?": a formação acadêmica em psicologia na perspectiva do aluno. In L. L. Melo-Silva (Ed.), Arquitetura de uma ocupação: Vol. 1: orientação profissional. Teoria e técnica (pp. 387-406). São Paulo: Vetor.
Olenscki, C. B., \& Salibe, S. T. (1998) Identidade profissional. A metamorfose: de lagarta a borboleta. In Anais do Encontro Estadual de Clínicas-Escola: Construindo a Identidade Profissional: Competência e Ética, 6, 114-116.

Pires, L. H. S. (2008). Formação do psicólogo: perspectivas de alunos de um curso de graduação. Dissertação de Mestrado, Programa de Pós-Graduação em Psicologia, Faculdade de Filosofia, Ciências e Letras de Ribeirão Preto, Universidade de São Paulo, Ribeirão Preto, SP.

Praça, K. B. D., \& Novaes, H. G. V. (2004). A representação social do trabalho do psicólogo. Psicologia: Ciência e Profissão, 24(2), 32-47.

Santos, E. M. B. (2002). Aspectos identitários do psicólogo no serviço público de saúde (1989-2000). Dissertação de Mestrado, Programa de Pós-Graduação em Psicologia, Universidade São Marcos, São Paulo.

Santos, M. A. (2003). Profissão: psicoterapeuta - vicissitudes da formação acadêmica e da inserção no mercado de trabalho. In L. L. Melo-Silva (Ed.), Arquitetura de uma ocupação, Vol. 1. Orientação profissional. Teoria e técnica (pp. 153-172). São Paulo: Vetor.

Sawaia, B. B. (1999). Identidade: uma ideologia separatista? In B.B. Sawaia, As artimanhas da exclusão (pp. 119-127). Petrópolis, RJ: Vozes.

Schein, E. H. (1996). Identidade profissional: como ajustar suas inclinações a suas opções de trabalho (M. D. Black, trad.). São Paulo: Nobel.

Scorsolini-Comin, F., Souza, L. V., \& Santos, M. A. dos. (2008). Tornar-se psicólogo: experiência de estágio de psicooncologia em equipe multiprofissional. Revista Brasileira de Orientação Profissional, 9(2), 113-126.

Sipoli, L. (1991). Negociação da identidade profissional do psicólogo em um projeto multidisciplinar de ação comunitária rural. Dissertação de Mestrado, Programa de Pós-Graduação em Psicologia, Pontifícia Universidade Católica de São Paulo, São Paulo.

Super, D. E. (1980). A life-span, life-space approach to career development. Journal of Vocational Behavior, 16, 282-298.

Tescariolli, L. (1999). Identidade e profissão: um estudo sobre a identidade do psicólogo professor universitário e clínico. Dissertação de Mestrado, Programa de Pós-Graduação em Psicologia Social, Universidade de São Paulo, São Paulo.

Vilela, A. M. J. (1996). Formar-se psicólogo: como ser livre como um pássaro. Tese de Doutorado, Programa de PósGraduação em Psicologia Escolar e do Desenvolvimento Humano, Universidade de São Paulo, São Paulo.

Yalof, J. A. (2004). Consolidating a professional identity in the $21 \mathrm{st}$ century. The changing landscape of education and training in pschology and its implications for counseling centers. Journal of College Student Psychotherapy, 12(2), 3-22. Recuperado em 25 de maio de 2008, dehttp://www.ingentaconnect.com/ content/haworth/jcsp/2004/00000012/00000002/art00002

Yamamoto, O. H. (2007). Políticas sociais, terceiro setor e compromisso social: perspectivas e limites do trabalho do psicólogo. Psicologia e Sociedade, 19(1), 30-37.

Yamamoto, O. H., \& Cunha, I. M. F. F. O. (1998). O psicólogo em hospitais de Natal: uma caracterização preliminar. Psicologia: Reflexão e Crítica, 11(2), 345-362.

Yamamoto, O. H., Câmara, R. A., Silva, F. L., \& Dantas, C. M. B. (2001). Espaços, práticas: o que há de novo na psicologia no Rio Grande do Norte? Psicologia em Estudo, 6(2), 65-72. 